\title{
Frontal, temporal and lateralized brain function in children with attention-deficit hyperactivity disorder: A psychophysiological and neuropsychological viewpoint on development
}

\author{
R.D. Oades \\ University Clinic for Child and Adolescent Psychiatry (RLHK), Virchowstr. 174, 45147 Essen, Germany \\ 1998 Behavioural Brain Research, 94, 83-95.
}

\begin{abstract}
This article considers deficits in the selective aspects of perception underlying symptoms of impaired attention and impulsivity in children with attention-deficit hyperactivity syndrome (ADHD) in terms of frontal and temporal lobe function and cerebral asymmetry. Tomographic studies suggest a disturbed fronto-striatal function, but have neglected limbic contributions under activating conditions and are equivocal on the nature of apparent lateralized differences.

Neuropsychological and psychophysiological studies suggest that early and late stages of information processing are affected in both the frontal and temporal lobes and imply impaired intercortical dialog. Given the evidence for a normal specialization in global processing in the right and the processing of details in the left hemisphere, the lateralized impairment may progress from situational ADHD (impaired selective aspects of perception on the right) to pervasive ADHD (additional impairment in decision-making on the left).

Accordingly some ADHD children may experience an early negative neurodevelopmental influence that only appears as the brain region matures while others show a delayed development of CNS function.
\end{abstract}

Keywords: Attention-deficit hyperactivity disorder; Attention; Impulsivity; Frontal cortex; Temporal cortex; Lateralization; Event-related potentials

\section{Introduction}

\subsection{Subjects: clinical disturbance and function}

A patient with attention-deficit hyper-activity disorder (ADHD) may be mainly restless and impulsive or mainly attention-disordered; but he or she may have both motor and cognitive problems [18]. However, in any series of ADHD patients there are those who also show tics, enuresis and various sorts of learning and conduct disorders. Alongside these, aggression (externalizing features) and anxiety-depression (internalizing features) will be manifest. They all may have potentially confounding correlates in the CNS.

This provides a problem for assessing the results of laboratory studies. Comorbid conditions may be overtly excluded (e.g. conduct disorders), but sometimes are included, leaving the reader to assess the bias so incurred. A similar problem occurs where
ADHD children obtain lower IQ scores than their age-matched healthy counterparts. Is a group matched for IQ and age typical? Is it appropriate to match in this way if such groups mature at different rates, and this contributes to the expression of the condition? Does such a sample of children with a cluster of ADHD symptoms represent the syndrome, at large? These fine details are often overlooked in summary overviews.

\subsection{Schemes for interpreting ADHD symptoms}

Following recognition of the problems of ADHD children's ability to maintain attention and control impulsivity, Douglas [19] emphasized their difficulty in modulating effort and arousal, and their tendency to respond without waiting for feedback or reinforcement. Both features have repercussions in the control of motivation and emotion and directing attention. Barkley's recent review [4] strongly espoused an 
interpretation of these impairments in terms of executive dysfunction. This is the ability to plan for adaptive response on the basis of experience, to integrate cognitively a variety of events with their possible consequences over time. It is attributed to dorsolateral frontal cortex function on the basis of neurophysiological studies of delayed reinforcement learning in primates and neurological and PET studies of response planning in humans: affect and emotive input and output exert their influence through the adjacent orbitofrontal-amygdala axis [1, 84].

However, an emphasis on frontal control may lead to overlooking the other areas and functions with which the frontal cortex is in dialogue to achieve direction and control. For example, the very facilities of arousal and effort (and 'activation'), said by Douglas to be impaired in ADHD children, were the subject of a psychobiological synthesis of animal work over 20y ago by Pribram and McGuinness [87]. They described 3 intervening variables that influence information processing: arousal (physiological response to input), activation (tonic physiological readiness to respond) and their coordination through effort. These were attributed to function of the amygdala, basal ganglia and hippocampus, respectively [88]. This background informs work of Sergeant and colleagues $[108,109]$ who have argued that the crux of the problem in ADHD lies with the application of effort and the consequences for activation and response organisation. Their interpretation plays down the coordinating role of effort on arousal and learning and on search and decision-making. Arguably, this ignores the influences of comorbid features (e.g. anxiety) on adaptive intellectual function. But for the present discuss-ion a potential coordination role in the temporal lobe may be noted; this influences other subcortical regions and, in certain situations, is subject to executive influence.

Another scheme, based on Gray's model [35], proposes that the selective uptake of information in the brain occurs against a background of three competing behavioural systems, the behavioural inhibition system (BIS), the behavioural approach system (BAS) and the flight-fear system (FFS). The BIS is sensitive to secondarily aversive stimuli (innate fear, or extreme novelty) and mediates adaptive inhibitory responses. The BAS is more sensitive to secondarily appetitive stimuli and initiates exploration or approach (food, sexual partners). The FFS is sensitive to primary aversive stimuli and mediates escape or defensive aggression where appropriate. Quay and colleagues argue for a role of the BAS in core symptoms and opposing effects of comorbid internalizing or externalizing symptoms on an underfunctioning BIS [90]. This contrasts with the afore-mentioned schemes in emphasising that information processing is primary and motor control follows; that limbic (dys)function precedes (changes in) executive and motor control. Evidence will be considered for the involvement of the structure and function of the frontal and temporal-limbic lobes in the development of information-processing problems in ADHD patients ${ }^{11}$.

\section{Sources of pathology: structure and function}

\subsection{Tomography (structure)}

Is there direct evidence for differences in brain structure or cerebral activation in ADHD children? If so, then it would pro-vide a shortcut to the functions that psychologists should be examining. In practice, the strategy is usually the other way around. As there are practical limitations to the number of regions one can examine in tomographic investigations, their selection is usually based on neuro-psychological evidence of dysfunction.

\footnotetext{
${ }^{1}$ It is beyond the scope of this article to establish what may have given rise to the dysfunctions described. Nonetheless, in the absence of evidence for brain damage it is important to realise that there are two sorts of schemata for explaining the disturbances described. One posits an early negative neurodevelopmental influence that only appears as the brain region matures. This disposition could be of environmental or genetic origin. A second posits merely a delay in neural development that may be expressed in terms of synaptic pruning, growth factor secretion, hormones or enzyme systems necessary for establishing effective intercortical connectivity. Once expressed the former may have more durable effects than the latter.
} 
Early reports of diffuse differences in the brain structure of ADHD children were not confirmed after employing appropriate controls and quantitative assessment [110]. With the introduction of MRI, small (n_7-11) then larger samples ( $n \_50-57$ ) of ADHD boys were shown to have, on average, smaller anterior frontal cortices on the right - the opposite of what was expected [10, 12, 43]. Measurement techniques became more refined, but even recent work has not reported on groups based on developmental criteria, despite matching for age and sexual development (e.g. Tanner ratings). Is it feasible that the right-sided dysfunction alluded to here, is on the left? Perhaps the amount of synaptic pruning expected at this age has not occurred in the left prefrontal region of ADHD patients. For example, there is a report of decreased metabolic activation in left frontal areas in 14-y-old ADHD patients performing an auditory continuous performance task [131]. While these findings have been dismissed $[12,23]$, there is some consistency with early reports of decreased cerebral blood flow (CBF) in frontal, as well as the primary visual, auditory and sensorimotor cortices on the left in these patients; while a decrease on the right was reported for the caudate nucleus $[58,59,82]$. Although the findings of left prefrontal and parietal perfusion were replicated, in view of confounds with developmental age or IQ [113], their presence in other dysphasic children $[16,58]$ and the absence of correlations to externalizing or hyperactive symptoms, their specificity must remain equivocal [54].

There is also disagreement on whether the caudate is normally larger on the left or right $[12,45]$. How then should the 'loss' of asymmetry that both groups report be understood? If we accept that the larger caudate nucleus is on the right [12], then the decrease they report on the right is consistent with the decreased blood flow described above. But there is a recent description of decreased pallidal volume on the left in a small group of ADHD boys [3]. These data suggest that it might be more cautious to talk of a bilateral decrease in size. But, further problems remain for an explanation of ADHD in terms of unusual cerebral asymmetry. For example, the callosal area in patients is reported to be reduced specifically in midsagittal [44] or rostral regions [29], in the splenium [107] or not at all [12].

Areas that appear to remain relatively normal in ADHD patients include the temporal lobe (but see reference to the sensory cortices above). Both the size (MRI [16]) and the activity (SPECT [113]) of the temporal lobe and hippocampus are increased slightly on the right in healthy and in ADHD children. Regions of interest have not yet encompassed the brainstem up to the thalamus or major subdivisions of the frontal lobe. Reduced cerebellar volume has been reported [10], but such hypoplasias are found in several developmental disorders [82]).

In conclusion, tomographic studies point to a fronto-striatal disturbance in ADHD patients that may reflect an un-usual asymmetry of function, the nature of which remains equivocal. The proposal that it lies with the pre-orbito-frontal-caudate-thalamic circuit may point to a subtle differentiation from the frequently comorbid tic syndrome, where the parallel supplementary motor cortex/putamen /thalamic circuit may be affected $[12,83$, 115]. Such results should be viewed in the context of normal develop-ment, where there is a linear decrease of the volume of the cortex from prepuberty to adulthood [46], an even sharper decline across puberty affecting the basal ganglia [12] and an increase of brain weight across adolescence [6]. These developments reflect the pruning of synapses and dendrites and an increase in myelination $[6,42,47]$.

\subsection{Topography (system)}

The strength of MRI lies in the 3D-resol-ution of anatomic entities. In contrast, measures of electrical activity show millisecond time resolution, but poor spatial resolution. Thus, despite intensive development, functional imaging remains more a prerogative of the electrical (and magnetic) recording methods that shall now be discussed. 
The EEG has not yet proved of value in delineating sources of dysfunction in ADHD. Many clinicians find the EEG of ADHD children unremarkable in comparison to other features that they or the parents observe $[77,116]$. Reports of less power in the $8-10 \mathrm{~Hz}$ band $[21,111]$ and occasionally in the $\beta$-band $[8,67]$ could reflect problems of attention and arousal. These often respond to medication and ameliorate with increasing age $[96,126]$. Despite advances in EEG evaluation, it is more useful to examine stages of information processing in the averaged stimulus-elicited EEG, the event-related potential (ERP).

The earliest potentials in the brain-stem (latency $<10 \mathrm{~ms}$ ) and the 'midlatency' potentials $(<100 \mathrm{~ms})$ represent the synaptic stages for the passage of sensory information to the cortex. Brainstem latencies asymptote towards adult levels from about 1.5 years [22] and midlatency potentials from about 3 years [85]. While a less orderly progression may appear in children with developmental learning disabilities [63], studies of children with an exclusive diagnosis of ADHD are not known at this time. At the start of processing in the cortices ( $P 1$, latency $\sim 60 \mathrm{~ms}$ ) we found latencies were longer in children with tics, but shorter in those with ADHD [70]. The data (here or below) do not support a recent claim that slow conduction velocities are a feature of young ADHD children and attributable to delayed myelination [120].

Negative potentials are typically associated with excitatory processes and positive ones relate to reduced facilitation [105]. The arrival (registration) of information in the cortex is associated with local inhibitory processes (P1). The P1 itself may be similarly gated by prioritised processing of a prepulse just $100 \mathrm{~ms}$ earlier (prepulse inhibition, PPI). The following $\mathrm{N} 1$ peak represents the excitation ( $100 \mathrm{~ms}$ ) associated with the allocation of a channel for information processing out of the primary cortex [39,122]. The P2 ( 180 ms) from adjacent sensory cortex may represent the inhibition of other channels of information competing for attention and further processing $[39,70]$. Convergent CBF evidence [49] indicates that the allocation of resources and the focusing of attention occurs in the secondary cortices of the superior temporal gyrus. Here too are found the source dipoles of stimulus comparison processes (e.g. the deviant-minus-standard difference-waveform, or mismatch negativity (MMN), 150-220 ms). These are traces representing perceived stimulus differences. Processing then enters an 'endogenous' phase of controlled processing susceptible to conscious modulation. Successive N2 and P3 peaks represent categorisation and target-related information processing, and updating of the associations [39]. They can be recorded from several limbic and neocortical substrates. In both of the processes represented, the idea of a comparator plays a large role [35]. Frontal, executive control becomes an important feature in directing and monitoring the dialogue essential at this tertiary level of analysis.

The normal development of auditory ERPs from about 8 to $21 \mathrm{y}$ passes through 3 main stages $[73,119]$. The most marked is across puberty when an overlying frontal negativity of childhood (Nc) disappears; early peaks show a less diffuse topography and the frontal components become differentially sensitive to the type of stimulus. Topographic shifts are completed in early adolescence (e.g. N1 to the left, P2 anteriorly) and N2 becomes sensitive to attention conditions (diffuse versus focused), reflecting the ability to categorise information. Response times to target stimuli decrease. In late adolescence, P2 develops a reducing response to the type of tone and latencies continue to shorten, reflecting processing efficiency.

Auditory P1 and N1 maxima occur at frontal sites in both ADHD and healthy children [70]. Some laboratories find no size differences in the auditory or visual modality $[66,70]$, others have seen an absence of the small increase in the N1 amplitude, usually seen after a target stimulus in a discrimination (in three modalities, $[50,57,99])$. These differences probably reflect the pervasity of the symptoms in the different groups studied. But already at this early stage of processing latencies may be $20 \%$ shorter in ADHD patients $[70,101]$. 
In our laboratory, one of the more striking findings has been the larger P2 component in ADHD patients, shared by tic patients with comorbid symptoms of 'attention-deficit' (Fig. 1, [70], for auditory and visual stimuli $[33,101])$. Some reports describe smaller P2 peaks that normalise with response to psychostimulant therapy $[38,89,130]$. The difference likely reflects the presence or absence of certain symptom clusters in the ADHD constellation. For example, $\mathrm{P} 2$ has been reported to be larger in those with than in those without hyperactivity [41]. We suggested that large P2 peaks are consistent with impulsivity in these children, as we have observed small amplitudes in young patients with obsessive-compulsive disorder who are anything but impulsive [72]. In turn this is consistent with the proposal of fewer inhibitory checks from contextual information (processed in parallel) on the further processing of the stimulus that has caught the subject's attention. This explanation also accounts for the shorter latencies in ADHD patients recorded at later stages of processing, e.g. P2, N2, P3 [70, 93, 101].

N2 amplitudes, associated with stimulus categorization, decrease with increases of age and focused attention. Then how should one reconcile reports that ADHD patients have smaller N2 peaks than controls after visual $[101,106]$, but larger ones after auditory stimuli $[89,93]$ ? Although the reported age ranges overlap, two studies (using auditory stimuli) found that N2 was smaller in the younger patients, but larger than normal in the older ones $[38,98]$. This provides a striking parallel to a Kamin-blocking experiment (Section 3.3) where older patients were impaired, but younger ones were paradoxically better than controls in the suppression of learning about information superfluous to the task-a categorisation ability [68]. Thus while several features of ADHD information processing are consistent with developmental delays, a detailed explanation awaits a fuller account of the different stages of normal development, especially in the younger age range relevant for ADHD study.
Subtraction of the waveforms elicited by two different stimuli results in a 'difference wave', a neural trace of a comparator-function crucial to selective information processes. $M M N$, the dominant negativity 150-220 ms after the stimuli, results from comparing different non-target stimuli (see above). A comparison of target- with non-target-ERPs results in a processing negativity ( $\mathrm{PN}$, an attentional trace). Frontal peaks probably reflect generators in the temporal lobe [72]. Generalizing from the experience of four laboratories, the size of neither MMN nor PN is clearly different in ADHD patients. Small increases and decreases at best point to poorer modulation of comparator processes in ADHD patients [50, 52, 70, 100, 101]. However, we found a lateralisation for MMN at left frontal sites in ADHD patients that contrasted with a bias to the right in agematched controls (Fig. 1). (The bilateral adult distribution develops from about 14 years of age [73] and that for tic patients is more posterior.) A report on $\mathrm{PN}$ was complex, using both auditory and visual stimuli [100]. Broadly they also found ADHD patients with more PN on the left than controls and attributed this to less negativity in the target-elicited N2 peaks. As $\mathrm{MMN}$ is smaller in younger subjects, these data seem less likely to reflect delayed maturation of the mediating structure, but more an anomalous function on the right, consistent with tomographic evidence described above.

Studies in animals and brain-damaged human patients have shown that the temporoparietal border is crucial for the generation of the P3 [62]. The P3 is somewhat smaller in children with ADHD or dyslexia, autism, tics and other developmental disorders [57,130]. This holds for somatosensory and auditory but perhaps not visual stimuli $[50,101]$. We noted in a non-task oddball paradigm, with attention sustained, but in a non-demanding way, that the controls had a P3 maximum biased to the right side, as in adults; for the ADHD group maxima were in the midline [70]. As with the MMN, this suggests impaired function on the right, and as noted below, there is evidence of a right hemisphere impairment in other sustained attention tasks. 
A slow negative wave develops between a warning and an imperative stimulus

ERP

(P2 at circa $170-200 \mathrm{~ms})$

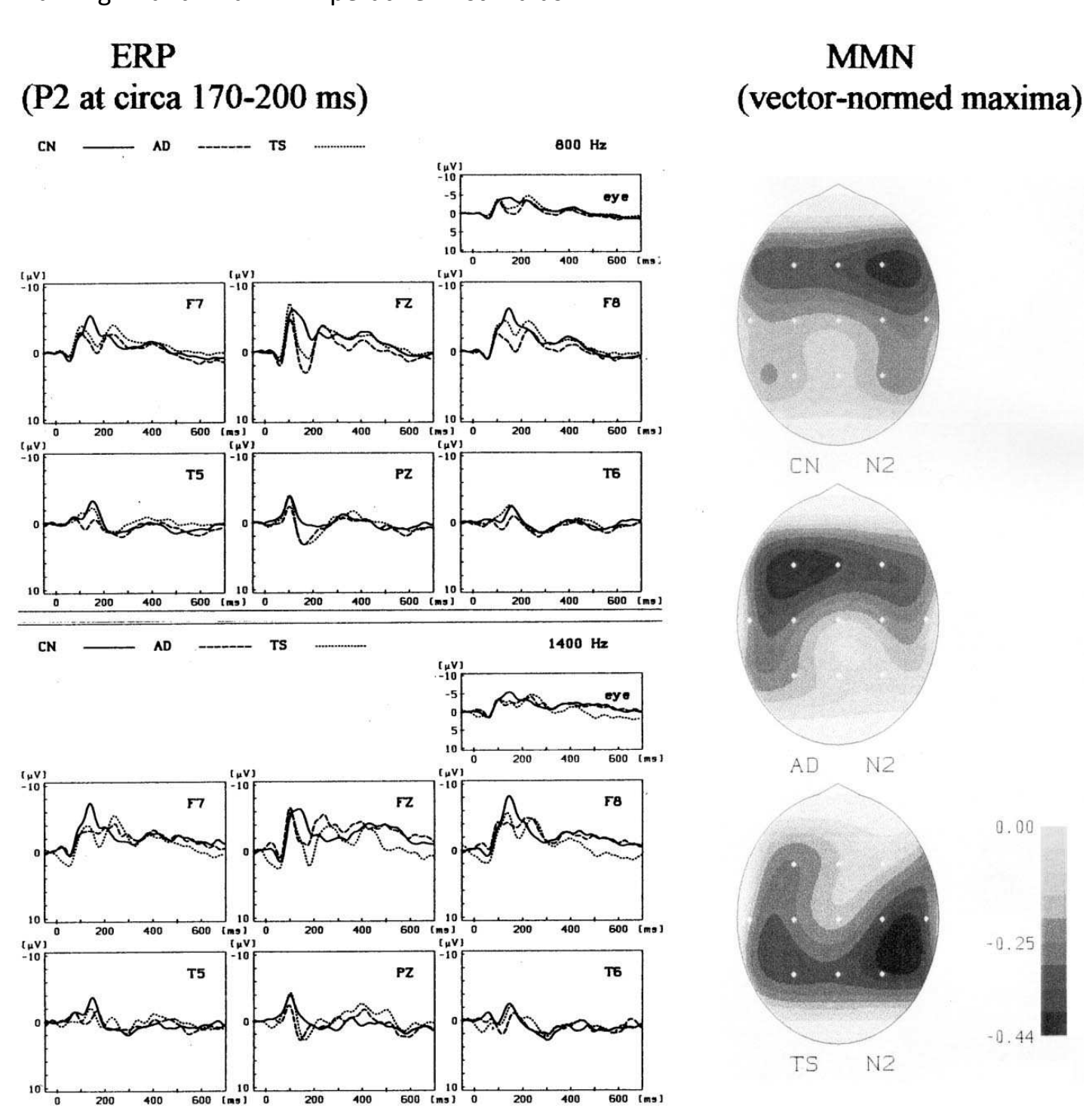

(contingent negative variation, CNV). It is more evident for auditory than visual

Fig. 1. On the left is shown the ERP for $700 \mathrm{~ms}$ after an 800 and a $1400 \mathrm{~Hz}$ tone at three frontal and three posterior recording sites on the skull averaged for three subject groups (negativity up, positivity down). The large P2 amplitude is illustrated for the two patients groups vs. the healthy children. On the right the topographical distribution (nose points up the page) of MMN is shown for three subject groups. Healthy children show a right frontal bias (shading) vs. the left sided bias in the ADHD patients. CN, healthy control; AD, ADHD; and TS, tic-syndrome children (details in [46], reprinted by permission of Elsevier).

stimuli and reflects anticipation, expectancy and task demands such as effort and sustained attention [13]. Its size is related to cognitive resources and declines with contextual distraction [94]; it is large at central sites, but a drop off over frontal sites is noted in children and in advanced age [20]. The overall amplitude did not differ in selected ADHD patients, yet was biased to the right, implying fewer resources on the left [129]. But decreases, with no lateralization at frontal sites, were found for those showing much restlessness, poor academic performance, externalizing [2] or tic symptoms [129]. Studies of other slow waves (e.g. motor readiness potential, postimperative negative variation) report less marked frontal contributions and subtle losses of asymmetry that imply right-sided impairments [96]. These changes may be ephemeral, but they recall a delay in terms of the first of the normal develop-mental stages described above. They 
are equivocal as to which side of the brain shows impaired function.

In conclusion, short ERP latencies in ADHD are not consistent with claims for slowed processing and delayed myelinisation. Rather it seems that information proceeds for further processing with reduced collateral contextual checks on early processing (large P2). Working memory trace formation (e.g. $\mathrm{MMN}$ ) and the completion of stimulus evaluation (P3) may be deficient in the right hemi-sphere. This is consistent with selected tomographic findings. It is not clear that the 'impairment' reflects a development-al delay in the sense that parts of the brain in ADHD patients function like those of healthy children at a younger age.

\section{Neuropsychology, information processing and attention}

A relatively ad hoc position will be taken here, disregarding a separation of sustained from selective attention, and emphasising that the selective aspect of perception occurs from the start [37]. Thus whether the situation concerns continuous performance (CPT), trace conditioning or learned inattention there is a requirement under more or less of an information load for selection of more from less relevant information. ERP work shows that selection occurs in primary and secondary sensory cortices; that it can occur earlier and undoubtedly occurs later in limbic areas where frontal dialogue may influence the outcome. From the previous sections we need to: (a) describe what type of frontal influence is impaired; (b) illuminate the right (left)-sided bias in ADHD dysfunction; and (c) seek clarification on a temporoparietal involvement.

\subsection{Frontal lobe involvement}

I shall be brief, as the subject has been reviewed recently $[4,112]$. On the one hand comparative neuropsychology shows that there are signs of poorer frontal function in ADHD patients. On the other hand authors diverge on the appropriate attribution of given psychological processes to particular biological mediation, and the specificity to nosology ${ }^{2}$.

The development of some normal frontal functions in groups of 7-8, 9-12 and 13-15year-olds was charted by Levin et al. [56]. Between the first two groups there was a big improvement in decision-making (card-sorting categories, errors of commission on go: no-go tasks). From 12 y-of-age hypothesis testing became more refined (20-questions, Towerof-London) and intra-dimensional shifting more efficient. Studies of a variety of ADHD patients indeed show impairments in the performance of tasks that are classically claimed to reflect frontal function. These include verbal fluency and recall $[25,34,116]$, trails $B[7,112]$ and the Wisconsin card-sorting test. We also noted unsophisticated 20questions performance and, for their age, non-adaptive cognitive shifting in ADHD patients (unpublished data). Eight of 12 reports on card-sorting found increased perseveration or that fewer categories were formed by ADHD children (i.e. poor extradimensional shifts; [4]). Barkley attributed some of the variety to the variable participation of more severely affected patients with a family history of the syndrome. But, developmental delay, estimated at 3 years [112], is as likely to be a crucial factor. Many with experience of the test have noted that: (a) patients' performance varies a lot; (b) non-perseverative errors are numerous; and (c) variation is introduced by the experimenter who often has difficulty abiding by the instructions. Nonetheless, a careful study of some 50 ADHD patients (6-13 years) with above normal intelligence showed, after attempting to balance for cognitive abilities, that the patients often had a problem with

\footnotetext{
${ }^{2}$ Neuropsychological tests purport to highlight a definable function as requiring a definable part of the CNS for normal expression in adults. Test validity has usually depended on the deficits recorded after brain damage, but is being refined by various tomographic procedures. Performance deficits in development do not without reason imply damage, merely that the characteristic adult cognitive style has not been achieved. There may be numerous reasons for this ranging from acute or developmental insults through normal or delayed ontogeny to the need to recruit the activity of more CNS systems than the situation allowed (see developmental ERP topography [73]).
} 
maintaining set and with fluency [17,91]. As $\sim 40 \%$ of these performed more than one standard deviation worse than the norm, the authors suspected executive dysfunction.

However, with the simplicity and consistency of these results, it is often overlooked that temporal lobe function is involved in many of these tests. Thus, the left prefrontal cortex is activated during word generation in healthy adults, but at the same time there is a bilateral decrease of activity in the auditory and superior temporal gyri [26]. Impairments for verbal memory and categorisation in a group of chronic schizophrenics correlated with MRIdetermined decreases in the parahippocampal and superior temporal gyri [65]. During cardsorting adults show increases of blood-flow in (left) frontal regions, but also bilaterally in posterior temporal regions [92]. A comparison of patients with MRI-checked hippocampal sclerosis, lateral temporal seizures and unilateral frontal damage reported that both frontal and temporal groups had decreased measures of fluency, and it was the hippocampal group that recorded fewer categories and more perseveration in cardsorting [14]. In conclusion, there are signs of impaired frontal function in ADHD children that may extend to some complex executive functions. But, similar functions may be relatively intact (e.g. verbal working memory span [114]) or extend outside the frontal domain. The latter would be anticipated by comparison of impaired checking processes in the stop-signal: no-go task [75] and impaired checks in secondary cortices, deduced from ERP recordings (Section 2.2). It may be the dialogue of the frontal with the temporal lobes that gives rise to function and dysfunction. Taking a summary of soft signs as a criterion for deciding on regions of interest for MRI examination can mislead.

\subsection{Lateralization and frontal function}

It is a common finding in a CPT that ADHD children notice fewer targets (d-prime worse) and often commit more errors (b-criterion worse). The impairment may not deteriorate over time (no special vigilance deficit), but may reflect a momentary concentration problem [15, 74]. By definition the impairments in terms of signal detection are perceptual deficits, although a number of other intervening variables, such as motivation can influence their expression [80]. Deficits are more evident in externally paced tests, vary with the task demands (e.g. CPT-x, or -ax or -double forms [69]) and may be found in a number of other psychopathological conditions in the young and old.

A differential motivational influence on the performance of healthy and ADHD children with externalising problems may be demonstrable [121], but is likely to vary with nosological and demographic variables as well as reinforcement contingency. Immediate feedback on the CPT is perceived as helpful by most young children, but after about 14 years it is perceived as interference (unpubl. data). Experience with biofeedback therapy suggests that ADHD children can use and may indeed depend more on the external help [95]. This is seen as an exogenous 'Ersatz' for the weaklyexpressed endogenous point of reference necessary for executive control (see also eye movements and fixation point, below). Motivational influences may be a part of the non-specific spectrum of the CPT impairment, as suggested for the CPT deficits in schizophrenia [104]. Studies of brain damage in children and adults $[40,125]$, suggest that an influence of the right frontal lobes in motivation is likely. This conclusion parallels the conclusion of impaired right hemi-sphere visuospatial function in CPT-impaired ADHD children [27]. It is more parsimonious to describe motivation, like visuospatial abilities, as adjunctive if not integral to a right hemisphere role in perception and attention.

For example, on a self-paced cancellation test, ADHD children made more errors on the left side, implying a right hemisphere source of the problem [124]. Indeed, in PET studies with adults, CPT performance increases blood flow specifically in frontal areas (e.g. Brodman area, BA 9) and the parietal borders on the right [79]. Reaction time studies during sustained and directed attention confirm the importance of the right hemisphere $[25,127]$. Indeed slowed reaction times were noted 
particularly in association with orbital frontal aneurysm [32]. This is of interest in that not only are slowed responses notable for ADHD patients but the orbital-frontal function is so often associated with the integration of affect and emotive stimuli.

Recent PET work showed that the particular province of the right hemisphere lies in global or gestalt perception (Brodman area 18) while that of the left lies in local processing ('the trees for the forest': e.g. the inferior occipital gyrus [24]). This raises the interesting question of whether widespread signal detection problems reflect a dysfunction on the right, while the less frequent signal identification problems, perhaps only in cases with pervasive symptoms, reflect left-sided dysfunction. Recently, a study of the effects of frontal brain damage showed that where patients became more prefrontal area and in the head of the anterior caudate nucleus [31].

Animal studies are supportive of this scheme, but emphasize the need to look at wider interactions for a full explanation of the neurobiological contributions to these sorts of task impairments. For example, records from prefrontal neurones in monkeys have demonstrated firing patterns in preparation for a response to a target that vary with the difficulty and effort required for a perceptual discrimination [55]. This responsivity is influenced by a dopaminergic innervation with lateralised patterns of receptor distribution (e.g. more D2 sites on the left than the right [28]). In rats, damage to dopaminergic systems results in more omission errors and increased reaction time; a feature that can be counteracted by subthalamic damage at the cost of more errors of commission [5]. Such impulsivity has also been noted after damage to the anterior cingulate area of rodents [64]. In return this result models what we know from human CBF studies: cingulate activation is important in target detection, go/no-go and Stroop performance [78], and dysfunction is thus implied for impulsive ADHD performance in stop-go and Stroop tasks (eight out of nine studies noted in [4]). sensitive to irrelevant stimuli ( $\beta$-criterion increased), MRI images showed that the locus of damage lay in the left superior rodents noted that individuals that did not show clear side preferences were those that were the most behaviourally active and the poorest learners [30]. Perhaps lateralization, or its absence, within the cortical-subcortical circuit is significant for the appearance of ADHDlike symptoms. An involvement of limbic or temporal lobe elements in the 'decision-making process' is considered in Section 3.3. First, control of eyemovements so important for directing and maintaining attention will be discussed.

Frontal brain damage in adults often affects the frontal eye field (FEF) and makes it difficult to suppress saccadic eye-movements [25]. A study of the ability of 20 ADHD children to make

Thus, comparative neuropsychology implicates components of the frontalstriatal thalamic circuit in sustained attention. Indeed, early work with

saccades toward or away (antisaccade) from a target showed no major impairment, but there was a lack of the asymmetry that healthy children showed, with shorter latencies to the left [97]. The implication is that the right FEF functions differently in ADHD (Fig. 2); poor executive control was also implicated in the disproportionate increase of anti-saccade errors recorded when the reference fixation point was switched off. A similar impression was gained in studies of the covert orienting of attention (COA). ADHD children showed more anticipatory responses [9] and a reduced ability to sustain attention to the cued location [118]. The COA task compares reaction times with spotting targets on one side or the other after a cue that sometimes indicates the false location. 'Exogenous' cues occur at the putative location while 'endogenous' cues (e.g. an arrow) appear by the fixation point. Clear cut group differences are not seen on these tasks $[66,81]$. But subtle differences in the effect of cue validity relating to the left visual field (right hemisphere function), with respect to control performance, are suggestive of poor executive control of the attention 
switch $[9,36,81]$. The pattern shown in Fig. 2 relates to the endogenous condition, and is reminiscent of the FEF result (above), but is opposite to the result with peripheral cues, which may favour children with impulsive tendencies

In conclusion, global aspects of attention and motivation are under right frontal control, while detailed aspects relating to identification include left frontal function. These functions may be differentially impaired with the severity of ADHD. The context of these experiments concerns two putative attention systems [86]. The posterior one mediates attention shifts; the thalamic pulvinar nucleus is necessary to maintain attention, the posterior parietal cortex allows the disengagement of the attentional focus and the superior colliculus mediates the shift. The cingulate and basal ganglia of the anterior system interact at the executive level designating the priority and allocation of cognitive function. Against this background it may be seen that the evidence touches on poor executive control in ADHD patients, but rarely have subcortical roles been studied. The eye-movement data point to weaker control in the right hemisphere. But, the interaction with medial temporal lobe structures has barely been broached; their function-dysfunction, implicated by ERP data, will now be discussed.

\subsection{Lateralization and temporal lobe function}

The PET study of adults, on global and local processing (above), also investigated the divided attention situation that is arguably more pertinent to real life than some of the lab tests discussed [24]. The areas activated were the right temporal-parietal-occipital junction (BA 22-39). These are areas implicated in stimulus evaluation processes on the basis of ERP records from brain-damaged adults (e.g. P3, [123]). Temporal lobectomy on the left resulted in larger P2 amplitudes (reminiscent of ADHD). Patients with damage on the right made more errors and traded accuracy for speed. If not exactly like ADHD patients, this is reminiscent of impulsive behaviour [103]. Further, metabolism in the left somatosensory cortex, primary auditory (temporal) cortex and occipital regions was reported to be lower on the left in ADHD [82].

A major component of the medial temporal lobe, the hippocampus, does not achieve mature function in normal children in the first decade. This is one conclusion from developmental studies of
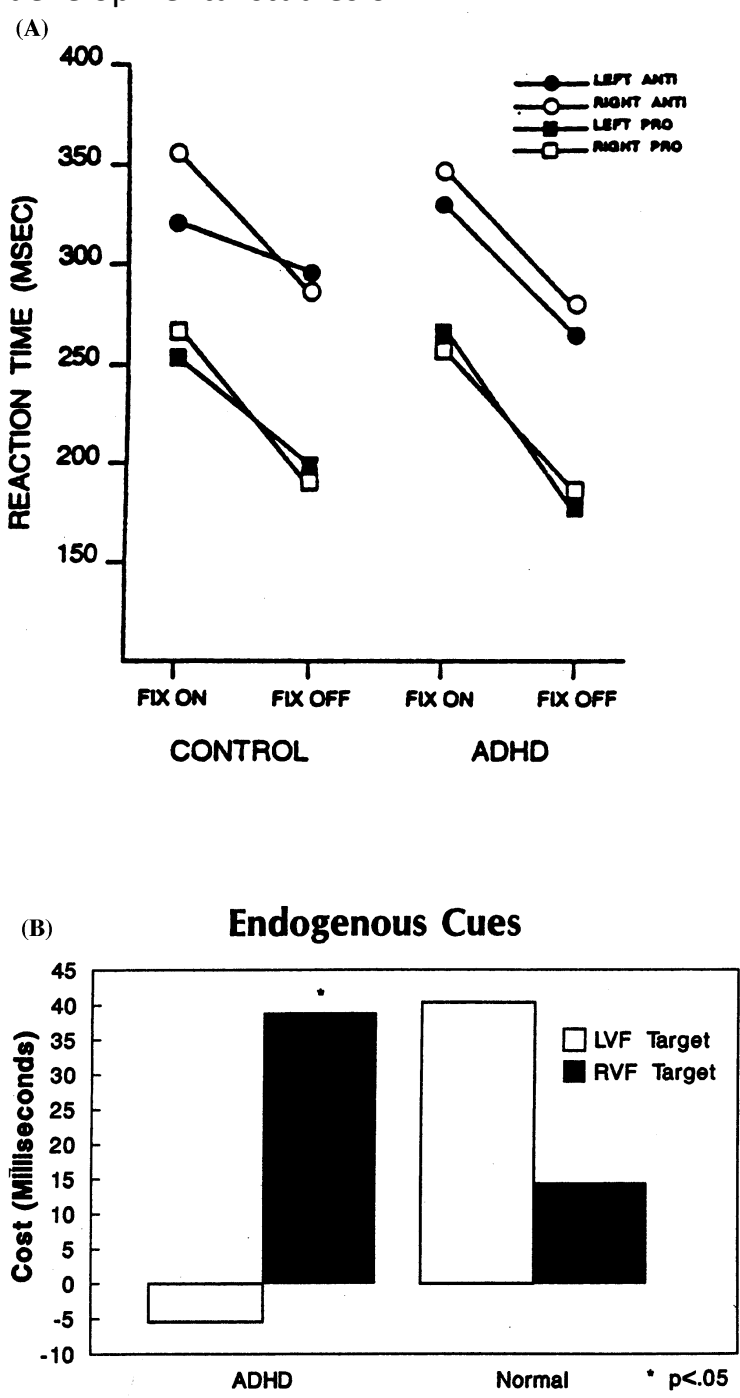

Fig. 2. The upper figure (A) shows the median saccade latencies for error-free trials as a function of ADHD and control group, task direction of eye-movement and presenceabsence of fixation stimulus. Note the leftright asymmetry for antisaccades in controls (upper left) that is absent in ADHD patients (upper right [112]). The lower figure (B) illustrate the costs (reaction time to invalidly vs. validly cued target) for targets in the left and right visual field for ADHD and healthy control children. Note again the absence of the asymmetry shown by controls. (details in [113], reprinted by permission of Elsevier, 
copyright by the Society of Biological Psychiatry).

trace conditioning [128], a form of associative learning that requires hippocampal function in animals. Both latent inhibition (LI) and conditioned blocking (CB) tests of learned inattention

do not achieve mature levels in normal children until the second decade $[48,71]$. LI is a test of the ability to 'unlearn' that a stimulus has no consequence and acquire an appropriate response to a new contingency. $\mathrm{CB}$ tests the normal ability not to learn about a superfluous stimulus added after conditioning to another has started. Both depend on the hippocampus and related mesolimbic structures in animals. ADHD children perform both tasks inadequately compared with healthy age-matched children, but not consistently poorly like younger and older children with complex tics. This provides an indirect argument for a developmental delay in mesolimbic (non-frontal) function [60, 67].

Are there other signs for a temporal lobe involvement? There are many reports of poorer recall, especially of non-verbal material, for ADHD patients (e.g. ReyeOsterreith figures $[8,34,51])$ and those with comorbid tic problems [61]. But often marked differences are not found [91,112]. Kinsbourne pointed out that the problems lay more with the attentionally disturbed than the restless patient [51]. But, as recall tends to be poorer in children of lower $I Q$, poor performance may merely reflect disorganisation or perhaps a lack of frontal control rather than temporal lobe function.

Lastly, could prepulse inhibition (PPI), as a measure of the gating of the flow of information, implicate temporal function? In this test a click 100-300 ms before a salient stimulus reduces the response to the second stimulus (e.g. startle-blink or P1 ERP). Normal PPI matures between 8 and 12 years of age [11]. In other young patients we found PPI of the P1 component was altered at temporal sites [102], but only the startle form has been used in ADHD, who responded almost normally, showing some $40-50 \%$ inhibition
$[11,117]$. However, quite common comorbidities do seem to interfere with gating (e.g. enuresis, tic $[11,76])$. If these results are confirmed, the reassuring conclusion may be that the initial flow of information into the sensory cortices is unimpaired in ADHD.

In conclusion, temporal lobe function may not be normal in ADHD-notably on the right in severe cases and less so on the left in others. It is apparent as an impairment of stimulus comparison (difference waves) and is important in making decisions in divided attention situations. It is an appropriate site for executive influences on the prioritising of information processing. Weak influences may be reflected in large P2 ERPs, but only extend to memorial function (medial temporal lobe) if resources or intellectual abilities are otherwise limited or to earlier primary processing (PPI) in the case of complications with comorbid symptoms.

\section{Conclusions}

Some features of information processing by patients with pervasive ADHD may reflect early neurodevelopmental influences that are not revealed until the structure is mature enough to show normal function [53]. Examples include cases with reduced cerebral activation on the left, especially in situations where fine resolution of detail is required. Other disturbances of information processing are suggestive of developmental delays (e.g. stimulus comparison, $\mathrm{MMN}$; set acquisition, CNV and the ability to categorize). The question of frontal versus temporal lobe involvement is confounded by the need for (frontal) executive function to direct other (temporal or limbic) activity. Depending on the nature of the task this may show up with a frontal bias (e.g. the ability to respond to nogo signals) or a temporal bias (e.g. large P2 response to non-pertinent stimuli). Future studies should recognize that lateralized functional impairments may appear because of the preferred involvement of the right hemisphere in global function and the left in the detail. The ascription of frontal or temporal lobe function-dysfunction to children should be based less on the neuropsychologist's experience with adults 
and more on the comparative development of specific measures alongside tomographictopographic backup. Such comparative work requires 'comparison' groups matched for biological development and ability, as well as contrasting age and comorbid pathology.

\section{References}

[1] Adolphs R, Tranel D, Damasio H, Damasio A. Impaired recognition of emotion in facial expressions following bilateral damage to the human amygdala. Nature 1994;372:669-72.

[2] Aydin C, Idiman F, Idiman E. Contingent negative variation in normal children and in children with attention deficit disorder. Adv Biol Psychiatry 1987;16:178-95.

[3] Aylward EH, Reiss AL, Reader MJ, Singer HS, Brown JE, Denckla MB. Basal ganglia volumes in children with attention deficit hyperactivity disorder. J Child Neurol 1996;11:112-5.

[4] Barkley RA. Behavioral inhibition, sustained attention and executive functions: constructing a unifying theory of ADHD. Psychol Bull 1997;121:65-94.

[5] Baunez C, Nieoullon A, Amalric M. In a rat model of Parkinsonism, lesions of the subthalamus nucleus reverse increases of reaction time. J Neurosci 995;15: 6531-42.

[6] Benes FM, Turtle M, Khan Y, Farol $O$. Myelination of a key relay zone in the hippocampal formation occurs in the human brain during childhood, adolescence and adulthood. Arch Gen Psychiatry 1994;51: 477-84.

[7] Boucugnani LL, Jones RW. Behaviors analogous to frontal lobe dysfunction in children with attention deficit hyper-activity disorder. Arch Clin Neuropsychol 1989;4:16173.

[8] Caresia L, Pugnetti L, Besana R, Barteselli F, Cazullo AG, Musetti L, Scarone S. EEG and clinical findings during pemoline treatment in children and adults with attention deficit disorder. Neuropsychobiology 1984;11:15867.

[9] Carter CS, Krener P, Chaderjian M, Northcutt C, Wolfe V. Asymmetrical visual-spatial attentional performance in ADHD: evidence for a right hemisphere deficit. Biol Psychiatry 1995;37:789-97.
[10] Castellanos FX, Giedd JN, Eckburg P, Marsh WL, Vaituzis AC, Kaysen D, Hamburger SD, Rapoport JL. Quantitative morphology of the caudate nucleus in attention-deficit hyperactivity disorder. Am J Psychiatry 1994;151:1791-6.

[11] Castellanos FX, Fine EJ, Kaysen D, Marsh WL, Rapoport JL, Hallett M. Sensorimotor gating in boys with Tourette's syndrome and ADHD: preliminary results. Biol Psychiatry 1996;39: 33-41.

[12] Castellanos FX, Giedd JN, Marsh JL, Hamburger SD, Vaituzis AC, Dickstein DP, Sarfatti SE, Vauss YC, Snell JW, Lange N, Kayen D, Krain AL, Ritchie GF, Rajapakse JC, Rapoport $\mathrm{JL}$. Quantitative brain magnetic resonance imaging in attention deficit hyperactivity disorder. Arch Gen Psychiatry 1996;53:607616.

[13] Chao LL, Nielsen-Bohlman L, Knight RT. Auditory event-related potentials dissociate early and late memory processes. Electroencephalogr Clin Neurophysiol 1995;96:157-68.

[14] Corcoran R, Upton D. A role for the hippocampus in card sorting? Cortex 1993;29:293-304.

[15] Corkum PV, Siegel LS. Is the continuous performance task a valuable research tool for use with children with attention deficithyperactivity disorder? J Child Psychol Psychiatry. 1993;34:1217-39.

[16] Denays $R$, Tondeur M, Foulon M, Verstraeten F, Ham H, Piepsz A, Noel P. Regional brain blood flow in congenital dysphasia: studies with technetium-99m HM-PAO SPECT. J Nucl Med 989;30: 1825-9.

[17] Denckla MB. Research on executive dysfunction in a neurodevelopmental context: application of clinical measures. Dev Neuropsychol 1996;12:5-15.

[18] Diagnostic and Statistical Manual IV (DSMIV). Washington DC: American Psychiatric Association, 1994.

[19] Douglas VI. Cognitive deficits in children with attention deficit disorder with hyperactivity. In: Bloomingdale LM, Sergeant J, editors. Attention Deficit Disorder: Criteria, Cognition, Intervention. London: Pergamon, 1988:65-82.

[20] Dustman RE, Shearer DE, Emmerson RY. EEG and event-related potentials in normal aging. Prog Neurobiol 993;41: 369-401. 
[21] Dykman RA, Holcomb PJ, Oglesby DM, Ackerman PT. Electrocortical frequencies in hyperactives, learning disabled, mixed and normal children. Biol Psychiatry 1982;17:67586.

[22] Eggermont JJ. On the rate of maturation of sensory evoked potentials. Electroencephalogr Clin Neurophysiol 1988;70:293-305.

[23] Ernst M, Liebenauer LL, King AC, Fitzgerald GA, Cohen RM, Zametkin AJ. Reduced brain metabolism in hyperactive girls. J Am Acad Child Adolesc Psychiatry 1994;33:858-68.

[24] Fink GR, Halligan PW, Marshall JC, Frith CD, Frackowiak RSJ, Dolan RJ. Where in the brain does visual attention select the forest and the trees? Nature 1996;382:626-8.

[25] Foster JK, Eskes GA, Stuss DT. The cognitive neuropsychology of attention: a frontal lobe perspective. Cogn Neuropsychol 1994;11:13347.

[26] Frith CD, Friston KJ, Liddle PF, Frackowiak RSJ. A PET study of word finding. Neuropsychologia 991;29:1137-48.

[27] Garcia-Sanchez C, Estevez-Gonzalez A, Suarez-Romero E, Junque C. Right hemisphere dysfunction in subjects with attention-deficit disorder with and without hyperactivity. J Child Neurol 1997;12:107-15.

[28] Giardino L. Right-left asymmetry of D1- and D2-receptor density is lost in the basal ganglia of old rats. Brain Res 1996;720:235-8.

[29] Giedd JN, Castellanos FX, Casey BJ, Kozuch P, King AC, Hamburger SD, Rapoport JL. Quantitative morphology of the corpus callosum in attention-deficit hyperactivity disorder. Am J Psychiatry 1994;151:665-9.

[30] Glick SD, Jerussi TP, Zimmerberg B. Behavioral and neuropharmacological correlates of nigrostriatal asymmetry in rats. In: Harnad S, et al., editors. Lateralization in the Nervous System. New York: Academic Press, 1977:213-49.

[31] Godefroy O, Rousseaux M. Divided and focussed attention in patients with lesion of the prefrontal cortex. Brain Cogn 1996;30: 155-74.

[32] Godefroy O, Cabaret $M$, Rousseaux $M$. Vigilance and effects of fatigability, practice and motivation on simple reaction time tests with patients with lesion of the frontal lobe. Neuropsychology 1994;32:983-90.

[33] Goodyear P, Hynd GW. Attention-deficit disorder with $(A D D / H)$ and without (ADD:WO) hyperactivity: behavioral and neuropsychological differentiation. J Clin Psychol 1992;21: 73-305.

[34] Gorenstein EE, Mammato CA, Sandy JM. Performance of inattentive-overactive children on selected measures of prefrontaltype function. J Clin Psychol 1989;45:619-32.

[35] Gray JA. The Psychology of Fear and Stress. Cambridge: Cambridge University Press, 1987.

[36] Greve KW, Williams MC, Haas WG, Littell RR, Reinoso $\mathrm{C}$. The role of attention in Wisconsin card sorting test performance. Arch Clin Neuropsychol 1996;11:215-22.

[37] Hackley SA, Woldorff MG, Hillyard SA. Combined use of micro-reflexes and eventrelated potentials as measures of auditory selective attention. Psychophysiology 1987;24:632-47.

[38] Halliday RA, Callaway E, Naylor H. Visual evoked potential changes induced by methylphenidate in hyperactive children: dose-response effects. Electroencephalogr Clin Neurophysiol 1983;55:258-67.

[39] Hansen JC, Hillyard SA. The temporal dynamics of human auditory selective attention. Psychophysiology 1988;25: 316-29.

[40] Heilman KM, Voeller KK, Nadeau SE. A possible pathophysiologic substrate of attention deficit hyperactivity disorder. J Child Neurol 1991;6(Suppl):76-81.

[41] Holcomb PJ, Ackerman PT, Dykman RA. Auditory event-related potentials in attention and reading-disabled boys. Int J Psychophysiol 1986;3:263-73.

[42] Huttenlocher PR. Morphometric study of human cerebral cortex development. Neuropsychologia 1990;28:517-27.

[43] Hynd GW, Semrud-Clikeman M, Lorys AR, Novey ES, Eliopulos D. Brain morphology in developmental dyslexia and attention deficit disorder: hyper-activity. Arch Neurol 1990;47:919-26.

[44] Hynd GW, Semrud-Clikeman M, Lorys AR, Novey ES, Eliopulos D, Lyytinen $H$. Corpus callosum morphology in attention deficit hyperactivity disorder: morphometric analysis of MRI. J Learn Disabil 1991;24:141-6.

[45] Hynd GW, Hern KL, Novey ES, Eliopulos D, Marshall R, Gonzalez JJ, Völler KS. Attention deficit hyperactivity disorder and asymmetry of the caudate nucleus. J Child Neurol 1993;8:339-47. 
[46] Jernigan TL, Tallal P. Late childhood changes in brain morphology observable with MRI. Dev Med Child Neurol 1990;32:379-85.

[47] Jernigan TL, Trauner DA, Hesselink JR, Tallal PA. Maturation of human cerebrum observed in vivo during adolescence. Brain 1991;114:2037-49.

[48] Kaniel S, Lubow RE. Latent inhibition: a developmental study. $\mathrm{Br} J$ Dev Psychol 1986;4:367-75.

[49] Kapur N, Friston KJ, Young A, Frith CD, Frackowiak RSJ. Activation of human hippocampal formation during memory for faces: a PET study. Cortex 995;31: 99-108.

[50] Kemner C, Verbaten MN, Cuperus JM, Camfferman $G$, van Engeland $\mathrm{H}$. Visual and somatosensory event-related brain potentials in autistic children and three different control groups. Electroencephalogr Clin Neurophysiol 1994;92:225-37.

[51] Kinsbourne M. Overfocussing: an apparent subtype of attention deficit-hyperactivity disorder. In: Amir N, et al., editors. Pediatric Neurology: Behavior and Cognition of the Child with Brain Dysfunction. Pediatric and Adolescent Medicine. Basel: Karger, 1991:1835.

[52] Klorman R, Brumaghim JT, Salzman LF, Borgstedt A, McBride MC, Loeb S. Effects of methylpenidate on processing negativities in patients with attention-deficit hyperactivity disorder. Psychophysiology 1990;27:328-37.

[53] Kolb B, Stewart J. Changes in the neonatal gonadal hormonal environment prevent behavioral sparing and alter cortical morphogenesis after early frontal cortex lesions in male and female rats. Behav Neurosci 1995;109:285-94.

[54] Kuperman S, Gaffney GR, Hamdan-Allen G, Preston DF, Venkatesh L. Neuroimaging in child and adolescent psychiatry. J Am Acad Child Psychiatry 1990;29:159-72.

[55] Lecas J-C. Prefrontal neurones sensitive to increased visual attention in the monkey. NeuroReport 1995;7:305-9.

[56] Levin HS, Culhane KA, Hartmann J, Evankovich K, Mattson AJ, Harward $H$, Ringholz G, Ewing-Cobbs L, Fletcher JM. Developmental changes in performance on tests of purported frontal lobe functioning. Dev Neuropsychol 1991; 7:377-95.

[57] Loiselle DL, Stamm JS, Maitinsky S, Whipple SC. Evoked potential and behavioral signs of attentive dysfunction in hyperactive boys. Psychophysiology 1980;17:193-201.

[58] Lou HC, Henriksen L, Bruhn P. Focal cerebral hypoperfusion in children with dysphasia and/or attention deficit disorder. Arch Neurology 1984;41:825-9.

[59] Lou HC, Henriksen L, Bruhn P, Borner H, Nielsen JB. Striatal dysfunction in attention deficit and hyperkinetic disorder. Arch Neurol 1989;46:48-52.

[60] Lubow RE, Josman ZE. Latent inhibition deficits in hyperactive children. J Child Psychol Psychiatry 1993;84:959-75.

[61] Matthews WS. Attention deficits and learning disabilities in children with Tourette's syndrome. Pediatr Ann 1988; 17:410-6.

[62] Molnar M. On the origin of the P3 eventrelated potential component. Int J Psychophysiol 1994;17:129-44.

[63] Morris GL, Obrzut JE, Coulthard-Morris L. Electroencephalographic and brain-stem evoked responses from learning disabled and control children. Dev Neuropsychol 1989;5:187-206.

[64] Muir JL, Everitt BJ, Robbins TW. The cerebral cortex of the rat and visual attention function: dissociable effects of medio-frontal, cingulate, anterior dorso-lateral and parietal cortex lesions on a five-choice serial reaction time task. Cereb Cortex 1996;6:470-81.

[65] Nestor PG, Shenton ME, McCarley RW, Haimson J, Smith RS, O'Donnell BF, Kimble M, Kikinis R, Jolesz FA. Neuropsychological correlates of MRI temporal lobe abnormalities in schizophrenia. Am J Psychiatry 1993;150:1849-55.

[66] Novak GP, Solanto M, Abikoff H. Spatial orienting and focused attention in attention deficit hyperactivity disorder.

[67] Oades RD. Attention deficit disorder with hyperactivity $(A D D H)$ : the contrib.-ution of catecholaminergic activity. Prog Neurobiol 1987;29:365-91.

[68] Oades RD, Müller B. The development of conditioned blocking \& and monoamine metabolism in children with attention-deficit hyperactivity disorder on complex tics and healthy controls: an exploratory analysis. Behav Brain Res 997;88:95-102.

[69] Oades RD, Bunk D, Röpcke R, Eggers C. Continuous performance errors: dopaminergic effects in medicated schizophrenic and 
hyperkinetic patients? Eur J Neurosci 1990;3 (Suppl):309.

[70] Oades RD, Dittmann-Balcar A, Schepker R, Eggers C, Zerbin D. Auditory event-related potentials (ERPs) and mismatch negativity (MMN) in healthy children and those with attention-deficit or Tourette/tic symptoms. Biol Psychol 1996;43:163-85.

[71] Oades RD, Röpcke B, Schepker R. A test of conditioned blocking and its development in childhood and adolescence: relationship to personality and monoamine metabolism. Dev Neuropsychol 1996;12:207-30.

[72] Oades RD, Zerbin D, Dittmann-Balcar A, Eggers C. Auditory event-related potential (ERP) and difference-wave topography in schizophrenic patients with: without active hallucinations and delusions: a comparison with young obsessive-compulsive disorder (OCD) and healthy subjects. Int J Psychophysiology 1996;22:185-214.

[73] Oades RD, Dittmann-Balcar A, Zerbin D. Development and topography of auditory event-related potentials (ERPs): mismatch and processing negativity in individuals 8-22 years of age. Psychophysiology 1997;34:677-93.

[74] O'Dougherty M, Nuechterlein K, Drew B. Hyperactive and hypoxic children: signal detection, sustained attention and behavior. J Abnorm Psychol 1984;93:178-91.

[75] Oosterlaan J, Sergeant J. Inhibition in ADHD, aggressive and anxious children: a biologically based model of child psychopathology. J Abnorm Child Psychol 1996;24:19-36.

[76] Ornitz EM, Hanna GL, de Traversay J. Prestimulation-induced startle modulation in attention-deficit hyperactivity disorder and nocturnal enuresis. Psychophysiology 1992;29:437-51.

[77] Palm L, Persson E, Bjerre I, Elqvist D, Blennow G. Sleep and wakefulness in preadolescent children with deficits of attention, motor control and perception. Acta Pediatr 1992;81:618-24.

[78] Pardo JV, Pardo PJ, Janer KW, Raichle ME. The anterior cingulate cortex mediates processing selection in the Stroop attentional conflict paradigm. Proc Natl Acad Sci USA 1990;87:256-9.

[79] Pardo JV, Fox PT, Raichle ME. Localization of a human system for sustained attention by positron emission tomography. Nature 1991;349:61-4.
[80] Pasuraman R, Davies DR. Varieties of Attention. Toronto: Academic Press, 1984.

[81] Pearson DA, Yaffee LS, Loveland KA, Norton AM. Covert visual attention in children with attention deficit hyperactivity disorder: evidence for developmental immaturity? Dev Psychopathol 1995;7:351-67.

[82] Peterson BS. Neuroimaging in child and adolescent neuropsychiatric disorders. J Am Acad Child Adolesc Psychiatry 1995;34:156076.

[83] Peterson BS, Riddle MA, Cohen DJ, Katz LD, Smith JC, Hardin MT, Leckman JF. Reduced basal ganglia volumes in Tourette's syndrome using three dimensional reconstruction techniques from magnetic resonance images. Neurology 1993;43:941-9.

[84] Petrides M, Alivisatos B, Meyer E, Evans AC. Functional activation of the human frontal cortex during the performance of verbal working memory tasks. Proc Natl Acad Sci USA 1993;90:878-82.

[85] Polich J, Starr A. Evoked potentials in aging. In: Albert ML, editor. Clinical Neurology of Aging. New York: Oxford University Press, 1984:149-77.

[86] Posner MI, Petersen SE. The attention system of the human brain. Annu Rev Neurosci 1991;13:25-42.

[87] Pribram KH, McGuinness D. Arousal, activation and effort in the control of attention. Psychol Rev 1975;82:116-49.

[88] Pribram KH, McGuinness D. Attention and para-attentional processing: Event-related potentials as tests of a model. Ann New York Acad Sci 1992;658:65-92.

[89] Prichep LS, Sutton S, Hakerem G. Evoked potentials in hyperkinetic and normal children under certainty and uncertainty: a placebo and methylphenidate study. Psychophysiology 1976;13:419-28.

[90] Quay HC. The behavioral reward and inhibition system in childhood behavior disorder. In: Bloomingdale LM, editor.

Attention Deficit Disorder. Oxford: Pergamon, 1988:176-86.

[91] Reader MJ, Harris EL, Schuerholz LJ, Denckla MB. Attention deficit hyperactivity disorder and executive dysfunction. Dev Neuropsychol 1994;10:493-512.

[92] Rezai K, Andreasen NC, Alliger RJ, Cohen G, Swayze VW, 
O'Leary DS. The neuropsychology of the prefrontal cortex. Arch Neurol 1993;50:63642.

[93] Robaey O, Breton F, Dugas M, Renault B. An event-related potential study of controlled and automatic processes in 6-8-year-old boys with attention-deficit hyperactivity disorder. Electroencephalogr Clin Neurophysiol 1992;82:330-40.

[94] Rockstroh B, Elbert T, Lutzenberger W, Birbaumer $\mathrm{N}$. The CNV distraction effect in long anticipation intervals. In: McCallum WC, et al., editors. Cerebral Psychophysiology: Studies in Event-Related Potentials, EEG, Suppl. 38. Amsterdam: Elsevier, 1986:265-7.

[95] Rockstroh B, Elbert T, Lutzenberger W, Birbaumer N. Biofeedback evaluation and therapy in children with attentional dysfunctions. In: Rothenberger A, editor. Brain and Behavior in Child Psychiatry. Berlin: Springer, 1990:345-57.

[96] Rothenberger A. Electrical brain activity in children with hyperkinetic syndrome: evidence of a frontal cortical dysfunction. In: Sergeant J, editor. Eunethydis; European Approaches to Hyperkinetic Disorder. Amsterdam: Fotorotar, 1995:255-70.

[97] Rothlind JC, Posner MI, Schaughnecy EA. Lateralized control of eye movements in attention deficit hyperactivity disorder. J Cogn Neurosci 1991;3:377-81.

[98] Satterfield JH, Braley BW. Evoked potentials and brain maturation in hyperactive and normal children. Electroencephalogr Clin Neurophysiol 1977;43:43-51.

[99] Satterfield JH, Schell AM, Backs RW, Hidaka $K C$. A cross-sectional and longitudinal study of age effects of electrophysiological measures in hyperactive and normal children. Biol Psychiatry 1984; 19:973-90.

[100] Satterfield JH, Schell AM, Nicholas TW, Backs RW. Topographic study of auditory event-related potentials in normal boys and boys with attention deficit disorder with hyperactivity. Psychophysiology 1988;25:591606.

[101] Satterfield JH, Schell AM, Nicholas T. Preferential processing of attended stimuli in attention-deficit hyperactivity disorder and normal boys. Psychophysiology 1994;31:1-10.

[102] Schall U, Schön A, Zerbin D, Eggers C, Oades RD. Event-related potentials during an auditory discrimination with prepulse inhibition in patients with schizophrenia, obsessive-compulsive disorder and healthy subjects. Int J Neurosci 1996;84:15-33.

[103] Scheffers M, Johnson R, Ruchkin DS. P300 in patients with unilateral temporal lobectomies: the effects of reduced stimulus quality. Psychophysiology 1991;28:274-84.

[104] Schmand B, Kuipers T, van der Gaag M, Bosveld J, Bulthuis F, Jellema M. Cognitive disorders and negative symptoms as correlates of motivational deficits in psychotic patients. Psychol Med 1994;24:869-84.

[105] Schupp HT, Lutzenberger W, Rau H, Birbaumer N. Positive shifts of event-related potentials: a state of cortical disfacilitation as reflected by the startle reflex probe. Electroencephalogr Clin Neurophysiol 1994;90:135-44.

[106] Schweiger E. Topographic brain mapping in children with attention deficit hyperactivity disorder. In: Proceedings of the Fourth European Congress of Psychology. Athens (Greece), 1995:53.

[107] Semrud-Clikeman M, Filipek PA, Biederman J, Steingard R, Kennedy D, Renshaw P, Bekken K. Attention-deficit hyperactivity disorder: magnetic resonance imaging morphometric analysis of the corpus callosum. J Am Acad Child Adolesc Psychiatry 1994;33:875-81.

[108] Sergeant JA. A theory of attention: an information processing perspective. In: Lyon GR, Krasnegor NA, editors. Attention, Memory and Executive Function. Baltimore, MD: Paul H. Brookes, 1995:57-69.

[109] Sergeant JA, van der Meere J. Convergence of approaches in localizing the hyperactivity deficit. In: Lahey BB, Kazdin AE, editors. Advances in Clinical Psychology, vol. 13. New York: Plenum, 1990:207-45.

[110] Shaywitz BA, Shaywitz SE, Byrne T, Cohen DJ, Rothman S. Attention deficit disorder: quantitative analysis of CT. Neurology 1983;33:1500-3.

[111] Shetty T. Alpha rhythms in the hyperkinetic child. Nature 1971;234:476-8.

[112] Shue KL, Douglas VI. Attention deficit hyperactivity disorder and the frontal lobe syndrome. Brain Cogn 1992;20:104-24.

[113] Sieg KG, Gaffney GR, Preston DF, Hellings JA. SPECT brain imaging abnormalities in attention deficit hyperactivity disorder. Clin Nucl Med 1995;20:55-60. 
[114] Siegel LS, Ryan EB. The development of working memory in normally achieving and subtypes of learning disabled children. Child Dev 1989;60:973-80.

[115] Singer HS, Reiss AL, Brown JE, Aylward EH, Shih B, Chee E, Harris EL, Reader MJ, Chase GA, Bryan N, Denckla MB. Volumetric MRI changes in basal ganglia of children with Tourette's syndrome. Neurology 1993;43: 950-6.

[116] Solanto MV. Neuropharmacological basis of stimulant drug action in attention deficit disorder with hyperactivity: a review and synthesis. Psychol Bull 1984;95:387-409.

[117] Sugawara M, Sadeghpour M, de Traversay J, Ornitz EM. Prestimulation-induced modulation of the P300 component of event-related potentials accompanying startle in children. Electroencephalogr Clin Neurophysiol 1994;90:201-13.

[118] Swanson JM, Posner MI, Potkin SG, Bonforte S, Youpa D, Cantwell D, Crinella F. Activating tasks for the study of visual-spatial attention in ADHD children: a cognitive anatomical approach. J Child Neurol 991;6 (Suppl):117-25.

[119] Taylor MJ, Pourcelot L. Potentiels evoques cognitifs chez l'enfant: developpement nomal et pathologique. Neurophysiol Clin 1995;25:130-45.

[120] Ucles P, Lorente S, Rosa F. Neurophysiological methods testing the psychoneural basis of attention deficit hyperactivity disorder. Child's Nerv Syst 1996;12:215-7.

[121] Van der Meere J, Hughes KA, Börger N, Sallee FR. The effect of reward on sustained attention in ADHD children with and without CD. In: Sergeant J, editor. Eunethydis; European Approaches to Hyperkinetic Disorder. Amsterdam: Fotorotar, 1995:24153.

[122] Vaughan HG, Arezzo JC. The neural basis of event-related potential. In: Picton TW, editor. Human Event-related Potentials. Amsterdam: Elsevier, 1988:45-96.

[123] Verleger R, Heide W, Butt C, Koempf D. Reduction of $\mathrm{P} 3 \mathrm{~b}$ in patients with temporalparietal lesions. Cogn Brain Res 1994;2:10316.

[124] Voeller KK, Heilman KM. Attention deficit disorder in children: a neglect syndrome? Neurology 1988;38:806-8.
[125] Voeller K, Hanson HA, Wendt RN. Facial affect recognition in children: a comparison of the performance of children with right and left hemisphere lesions. Neurology 1988;38:17448.

[126] Weiss G, Hechtman L. The hyperactive child syndrome. Science 1979;205:1348-54.

[127] Whitehead R. Right hemisphere processing superiority during sustained visual attention. J Cogn Neurosci 1991;3:329-34.

[128] Woodruff-Pak DS, Logan CG, Thompson RF. Neurobiological substrates of classical conditioning across the life span. Ann New York Acad Sci 990;608:150-74.

[129] Yordanova J, Dumais-Huber C, Rothenberger A. Coexistence of tics and hyperactivity in children: no additive effect at the psychophysiological level. Int J Psychophysiol 1996;21:121-33.

[130] Young ES, Perros P, Proce GW, Sadler T. Acute challenge ERP as a prognostic of stimulant therapy outcome in attention deficit hyperactivity disorder. Biol Psychiatry 1995;37:25-33.

[131] Zametkin AJ, Liebenauer LL, Fitzgerald GA, King AC, Minkunas DV, Herscovitch P, Yamada EM, Cohen RM. Brain metabolism in teenagers with attention-deficit hyperactivity disorder. Arch Gen Psychiatry 1993;50:333-40. 